\title{
Short communication: Interaction of energy balance, feed efficiency, early lactation health events, and fertility in first-lactation Holstein, Jersey, and reciprocal $F_{1}$ crossbred cows
}

\author{
K. M. Olson, ${ }^{1}$ B. G. Cassell, M. D. Hanigan, and R. E. Pearson \\ Department of Dairy Science, Virginia Polytechnic Institute and State University, Blacksburg 24061
}

\begin{abstract}
First-lactation Holstein (HH), Jersey (JJ), and crossbred cows (HJ and JH, with sire breed listed first, followed by dam breed) were observed for cumulative energy intake $\left(\mathrm{CEI}_{15}\right)$ and energy used for milk production $\left(\mathrm{CEL}_{15}\right)$ at wh 15 of lactation in addition to recordings of health problems and pregnancy. Cumulative energy balance $\left(\mathrm{CEB}_{15}\right)$ was calculated from $\mathrm{CEI}_{15}$ and estimates of expenditures at wk 15 of lactation. Feed efficiency $\left(\mathrm{FE}_{15}\right)$ was calculated by dividing $\mathrm{CEL}_{15}$ by $\mathrm{CEI}_{15}$. Data included 140 cows with 43, 34, 41, and 22 in the HH, HJ, JH, and JJ groups, respectively. The first incidence of displaced abomasum (DA), ketosis (KET), mastitis (MAST), and metritis (MET) was recorded in the first $100 \mathrm{~d}$ of lactation with an incidence of the disease coded as 1 and no incidence coded as 0 . Pregnancy (PREG) at d 150 was recorded as 1 if a cow had conceived by d 150 and 0 if she had not. Logistic regression was used to analyze health and fertility with fixed effects in the model including genetic group, linear and quadratic effects for age at calving, and year-season of freshening group. Pregnancy was analyzed with the same variables and the addition of $\mathrm{CEB}_{15}$. In other analyses, $\mathrm{CEB}_{15}, \mathrm{CEI}_{15}, \mathrm{CEL}_{15}$, and $\mathrm{FE}_{15}$ were response variables with the same explanatory variables plus health events (MAST, DA, MET, and KET), where each health event was a separate analysis. Genetic group effects were significant in the occurrence of MAST and a trend for MET, but were not significant for PREG, DA, and KET. Significant odds ratio for MAST was 19.6 for HJ cows when compared with that for HH cows. Thus, HJ cows were 19.6 times more likely than $\mathrm{HH}$ cows to have an incidence of MAST. The trend was for HJ and JH to have a lower odds ratio of MET than that of HH. No other genetic group effects were significant in any of the disease and PREG models. The linear and quadratic terms for age
\end{abstract}

Received May 12, 2010.

Accepted September 23, 2010.

${ }^{1}$ Corresponding author: katie.olson@ars.usda.gov at calving were not significant. An occurrence of MAST decreased $\mathrm{FE}_{15}$ by $5.2 \pm 2.2 \%$. Mastitis also decreased $\mathrm{CEI}_{15}$ and $\mathrm{CEL}_{15}$, but the compensatory reductions left the $\mathrm{CEB}_{15}$ unaffected. An occurrence of a DA decreased $\mathrm{CEI}_{15}$ and an incidence of KET decreased $\mathrm{CEB}_{15}$.

Key words: dairy cow, energy balance, health

High productivity of dairy cows has created increasing problems in fertility and health (Dunklee et al., 1994; Collard et al., 2000; Berry et al., 2003). Some producers have turned to crossbreeding to overcome some of these problems (Weigel and Barlass, 2003). Several studies have indicated that crossbreds have fewer health and lameness problems than purebred Holsteins (Heins et al., 2006; Anderson et al., 2007). Crossbreds have advantages in reproductive performance (Anderson et al., 2007; Heins et al., 2008). Anderson et al. (2007) found that Jersey-Holstein (JH) crosses had 22 fewer days open when compared with those of Holsteins in a pen study. Heins et al. (2008) also found JH crosses to have fewer days open than Holstein contemporaries.

Energy balance in early lactation has been linked to health (locomotive and digestive) and fertility problems (de Vries et al., 1999; Collard et al., 2000). Prolonged periods of negative energy balance can increase the use of body reserves, which can have detrimental effects on fertility and health (Hansen, 2000; Banos et al., 2006). Energy balance differences between breeds or a breed by energy balance interaction, or the combination of both could potentially cause health and fertility problems.

The literature includes few results of the relationships between breed groups, energy balance, and health disorders. Data sets of energy balance and health disorders are rare because of difficulties in collection of intake data and accurate recording of health disorders. The first objective of this study was to determine if there were differences between Holsteins, Jerseys, and reciprocal crosses in the first $100 \mathrm{~d}$ of their first lactation for displaced abomasums, mastitis, metritis, or ketosis. The second objective was to investigate the effects of health disorders on energy consumption, energy for lactation, feed efficiency, and energy balance. The 
Table 1. Means and SD by genetic group for cumulative energy intake $\left(\mathrm{CEI}_{15}\right)$, cumulative energy of lactation $\left(\mathrm{CEL}_{15}\right)$, cumulative energy balance $\left(\mathrm{CEB}_{15}\right)$, and feed efficiency $\left(\mathrm{FE}_{15}\right)$ at wk 15

\begin{tabular}{lcccc}
\hline & \multicolumn{4}{c}{ Breed $^{1}$} \\
\cline { 2 - 5 } Variable & HH & HJ & JH & JJ \\
\hline $\mathrm{CEI}_{15}\left(\mathrm{NE}_{\mathrm{L}}, \mathrm{Mcal}\right)$ & $2,932 \pm 350$ & $2,712 \pm 286$ & $2,747 \pm 224$ & $2,308 \pm 207$ \\
$\mathrm{CEL}_{15}\left(\mathrm{NE}_{\mathrm{L}}, \mathrm{Mcal}\right)$ & $2,005 \pm 345$ & $1,892 \pm 391$ & $1,955 \pm 261$ & $1,800 \pm 169$ \\
$\mathrm{CEB}_{15}\left(\mathrm{NE}_{\mathrm{L}}, \mathrm{Mcal}\right)$ & $-76 \pm 333$ & $-88 \pm 192$ & $-74 \pm 263$ & $-185 \pm 192$ \\
$\mathrm{FE}_{15}(\%)$ & $68.81 \pm 11.63$ & $69.28 \pm 9.40$ & $71.35 \pm 8.96$ & $78.43 \pm 8.94$ \\
\hline${ }^{1} \mathrm{HH}=$ Holstein; JJ = Jersey; HJ and JH = reciprocal crosses; breed of sire listed first, followed by breed of \\
dam.
\end{tabular}

final objective was to determine if genetic group and energy balance had an effect on pregnancy status by 150 DIM.

Cows from the study of Olson et al. (2010) were used in this study. The animal design was a classic diallel scheme with Holstein $(\mathbf{H})$ and Jersey $(\mathbf{J})$ foundation females mated to $4 \mathrm{H}$ bulls and $4 \mathrm{~J}$ bulls to create $\mathrm{JJ}$, $\mathrm{HH}, \mathrm{JH}$, and HJ genetic groups, where sire breed is listed first. Only $14 \mathrm{JJ}$ cows were available for this trial, partially due to lower success rates for $\mathrm{J}$ bulls compared with those of $\mathrm{H}$ bulls in the heterospermic fertilization study (Kasimanickam et al., 2006). Therefore, we added $8 \mathrm{JJ}$ that were daughters of project JJ, sired by 3 additional J bulls, thus increasing the total JJ to 22 cows. Data included 140 first-lactation cows with 43, 34, 41, and $22 \mathrm{HH}, \mathrm{HJ}, \mathrm{JH}$, and JJ cows, respectively. Feed intake data were collected between July 2005 and November 2008. Daily individual feed intakes were collected in 2-wk intervals out of every 6 -wk period during first lactation using the Calan door system (American Calan, Northwood, NH). Random regression was used to predict weekly average energy consumption, and further details and explanation can be found in Olson et al. (2010).

Genetic groups were housed, fed, and milked together. Random regression models, including genetic relationships between animals, were used to predict the weekly average energy consumed and energy expenditures for growth, milk production, and maintenance based on observed DMI, dietary nutrients, milk yield, and milk composition and NRC (2001) prediction equations. Further details of random regression models are described by Olson et al. (2010).

The energy intake term used was cumulative energy intake at wk $15\left(\mathbf{C E I}_{15}\right)$ of first lactation and was defined as the total amount of energy consumed between wk 3 and 15 of first lactation. Cumulative energy of lactation at wk $15\left(\mathbf{C E L}_{15}\right)$ was defined as the total amount of energy needed for lactation (accounting for milk, fat, and protein) needed between wk 3 and 15 of lactation. Feed efficiency $\left(\mathbf{F E}_{15}\right)$ was defined as $\mathrm{CEL}_{15}$ divided by $\mathrm{CEI}_{15}$. Energy balance was calcu- lated from the random regressions as energy consumed minus energy expended for growth, maintenance, and milk production. Cumulative energy balance at wk 15 $\left(\mathbf{C E B}_{15}\right)$ was the summation of energy balance between wh 3 and 15. Means and standard deviations for $\mathrm{CEI}_{15}, \mathrm{CEL}_{15}, \mathrm{CEB}_{15}$, and $\mathrm{FE}_{15}$ by genetic group are in Table 1. Further details on energy balance calculation are in Olson et al. (2010). The energy required to support pregnancy was not included in our measure of $\mathrm{CEB}_{15}$ because cows had to be $190 \mathrm{~d}$ in gestation before pregnancy requirements were used to calculate energy balance (NRC, 2001). No feed intakes were collected in the first $2 \mathrm{wk}$ of lactation; therefore, energy intake was not predicted before wk 3 .

Health events were recorded at the time of occurrence using PCDART software (DRMS, Raleigh, NC). Veterinary care for the Virginia Tech dairy was provided by veterinarians from the Virginia-Maryland Regional College of Veterinary Medicine. Health data retrieved from PCDART included the first incidence in the first $100 \mathrm{~d}$ of lactation of ketosis (KET), metritis (MET), displaced abomasum (DA), and mastitis (MAST). The DA included both right and left displaced abomasums. The MAST events were recorded as treatment of any udder infections by a veterinarian. Pregnancy (PREG) was defined as a cow conceiving by 150 DIM and was determined by breeding dates, pregnancy check, and, where possible, verified by a subsequent calving. Ketosis, DA, MET, MAST, and PREG were recorded in binary form as a 0 if a cow did not have the disease (or was not pregnant) and 1 if a cow did have the disease. Table 2 shows the incidences of DA, MET, MAST, KET, and PREG for each genetic group. The frequencies of 8.6 and $20 \%$ for KET and MAST, respectively, in this study were similar to the frequencies of 10 and $20 \%$ for KET and MAST, respectively, reported in Zwald et al. (2004). We found the overall frequency of DA was higher (10.7 vs. 3\%), but MET was lower (9.3 vs. 20\%) than frequencies reported by Zwald et al. (2004). Our results for DA ranged from 0 to $18 \%$ by genetic group. We observed no incidences of MET and DA in the JJ genetic group. 
Table 2. Incidence and frequencies of displaced abomasums (DA), mastitis, metritis, and ketosis in the first 100 DIM and pregnancy in the first 150 DIM in first-lactation Holsteins (HH), Jerseys (JJ), and reciprocal crosses (HJ and $\mathrm{JH})^{1}$

\begin{tabular}{|c|c|c|c|c|c|c|c|c|}
\hline \multirow[b]{2}{*}{ Condition } & \multicolumn{2}{|c|}{$\mathrm{HH}(\mathrm{n}=43)$} & \multicolumn{2}{|c|}{ HJ $(\mathrm{n}=34)$} & \multicolumn{2}{|c|}{$\mathrm{JH}(\mathrm{n}=41)$} & \multicolumn{2}{|c|}{$\mathrm{JJ}(\mathrm{n}=22)$} \\
\hline & Incidence & $\%$ & Incidence & $\%$ & Incidence & $\%$ & Incidence & $\%$ \\
\hline DA & 6 & 14 & 6 & 18 & 3 & 3 & 0 & 0 \\
\hline Ketosis & 4 & 9 & 3 & 9 & 3 & 7 & 2 & 9 \\
\hline Mastitis & 1 & 2 & 11 & 32 & 10 & 24 & 6 & 27 \\
\hline Metritis & 8 & 19 & 2 & 6 & 3 & 7 & 0 & 0 \\
\hline Pregnancy $^{2}$ & 24 & 56 & 23 & 68 & 27 & 66 & 15 & 68 \\
\hline
\end{tabular}

${ }^{1}$ Breed of sire listed first, followed by breed of dam.

${ }^{2}$ Defined as conceived by 150 DIM.

Incidence data corresponding to each health disorder and pregnancy were analyzed separately. A linear logistic regression model with the PROC LOGISTIC procedure of SAS (SAS Institute, 2004) was used to account for the binary nature of the data. The model equation used was

$\eta_{i j n}=\mu+Y S_{i}+G_{j}+\beta_{1} A A C_{i j n}+\beta_{2} A A{C_{i j n}}^{2}+e_{i j n}$,

where $\eta$ was the logit of observing the disease from the nth cow in the ith year-season $(Y S)$ of freshening group (3 seasons per year), jth genetic group $(G)$, with the nth cow's age at calving $(\boldsymbol{A} \boldsymbol{A} \boldsymbol{C}), \mu$ was the population mean, $\beta_{1}$ was a linear regression coefficient, $\beta_{2}$ was a quadratic regression coefficient, and $e_{i j n}$ was the random error term. The PREG analysis included the above terms with the addition of the explanatory variable $\mathrm{CEB}_{15}$. A Bonferroni adjustment was used for the confidence intervals of genetic groups to adjust for multiple comparisons. The Bonferroni adjustment divided the $\alpha$-value $(0.05)$ by 6 ( 6 comparisons between genetic groups). This resulted in a $0.0083 \alpha$-level to construct the confidence intervals of the genetic groups and an overall $\alpha$-value of 0.05 .

A general linear model with the PROC GLM procedure of SAS (SAS Institute, 2004) was used to investigate the effects of health events on $\mathrm{CEB}_{15}, \mathrm{CEI}_{15}$, $\mathrm{CEL}_{15}$, and $\mathrm{FE}_{15}$. The model equation was

$$
\begin{aligned}
Y_{i j n}=\mu+Y S_{i} & +G_{j}+\beta_{1} A A C_{i j n}+\beta_{2} A A C_{i j n}^{2} \\
& +H_{i j n}+e_{i j n}
\end{aligned}
$$

where $Y_{i j n}$ was the observation from the nth cow in the $i$ th year-season (YS) of freshening group (3 seasons per year), $j$ th genetic group $(G)$, linear and quadratic $A A C$ with regression coefficients $\beta_{1}$ and $\beta_{2}$, respectively, the $(H)$ health event of interest (expressed as 0 or 1 and run separately for KET, MAST, MET, DA, and PREG), population mean $\mu$, and the random error term $e_{i j n}$.
A Bonferroni adjustment was used for the confidence intervals of genetic groups to adjust for multiple comparisons.

Corresponding odds ratios for genetic groups for DA, MAST, MET, KET, and PREG are in Table 3. Genetic groups were statistically different for MAST $(P<0.05)$. The significant odds ratio for MAST was 19.56 with confidence intervals of 1.08 to 356.03 for the HJ in comparison to that of the HH. Thus, HJ were 19.56 times more likely than $\mathrm{HH}$ to have an incidence of mastitis in the first $100 \mathrm{~d}$ of lactation. A trend existed for the JJ to have a higher probability of having an incidence of MAST than the HH. No other significant differences for MAST were found between the genetic groups. The trend $(P<0.10)$ for MET was for JH and HJ groups to have a lower probability of an incidence of MET than did the HH group. No significant genetic group differences existed for KET, DA, and PREG.

The linear and quadratic terms for AAC were not significant for MET, KET, or MAST but showed trends $(P<0.10)$ for DA and PREG. The trend was for intermediate AAC to have a higher probability of PREG and a higher probability of a DA. Year-season of freshening group was not significant in any of the health traits but was significant in PREG. A trend ( $P$ $<0.10$ ) was observed for cows with higher $\mathrm{CEB}_{15}$ to have higher probability of PREG with an odds ratio of 1.01 for every unit increase of $\mathrm{CEB}_{15}$ (Mcal). Feed efficiency at wk 15 was not significant in the analysis for PREG status $(P=0.113)$.

The results for the analyses of health effects on $\mathrm{CEI}_{15}$, $\mathrm{CEL}_{15}, \mathrm{CEB}_{15}$, and $\mathrm{FE}_{15}$ are in Table 4. An incidence of DA decreased $\mathrm{CEI}_{15}$ by $185 \pm 73 \mathrm{Mcal}$ and a MAST event decreased $\mathrm{CEI}_{15}$ by $120 \pm 55 \mathrm{Mcal}$. These health events affected feed intake enough to significantly ( $\mathrm{P}$ $<0.05)$ reduce $\mathrm{CEI}_{15}$. Mastitis, DA, and MET did not significantly $(\mathrm{P}>0.1)$ affect $\mathrm{CEB}_{15}$. However, the effects of KET on $\mathrm{CEB}_{15}$ were significant, as an incidence of KET decreased $\mathrm{CEB}_{15}$ by $236 \pm 85$ Mcal. All KET events occurred in the first 2 mo of lactation. The effect 
Table 3. Odds ratios (OR) and associated CI for genetic groups ${ }^{1}$ (sire breed listed first, followed by dam breed) with the Holsteins (HH) group set as the base for having an incidence of displaced abomasum, ketosis, mastitis, metritis, and pregnancy

\begin{tabular}{|c|c|c|c|c|c|c|}
\hline Response $^{2}$ & OR & $\mathrm{CI}^{3}$ & OR & CI & OR & CI \\
\hline Ketosis & 1.283 & $0.107-15.394$ & 0.458 & $0.036-5.814$ & 0.536 & $0.026-10.857$ \\
\hline Mastitis & 19.56 & $1.08-356.03$ & 14.40 & $0.75-275.47$ & 21.49 & $0.93-495.02$ \\
\hline Metritis & 0.122 & $0.009-1.628$ & 0.115 & $0.008-1.633$ & \multicolumn{2}{|r|}{ NA } \\
\hline Pregnancy $^{5}$ & 1.373 & $0.308-5.803$ & 1.814 & $0.409-8.036$ & 2.597 & $0.360-18.710$ \\
\hline
\end{tabular}

${ }^{1} \mathrm{HH}=$ Holstein; JJ = Jersey; HJ and JH = reciprocal crosses; breed of sire listed first, followed by breed of dam.

${ }^{2}$ Effects in the model included genetic group, linear and quadratic for age at calving, and year-season freshening group.

${ }^{3} \mathrm{CI}$ was set to $\alpha=0.0083$ to account for multiple comparisons with the genetic groups.

${ }^{4} \mathrm{NA}=$ not applicable; the JJ group had no incidence of displaced abomasum and metritis.

${ }^{5}$ Defined as conceived by 150 DIM.

was strong enough that by wk 15, cumulative energy balance was still lower in cows that experienced a KET event than in those that did not. An incidence of MAST significantly $(P<0.05)$ reduced $\mathrm{CEL}_{15}$ with an estimate of $-220 \pm 65$ Mcal. The other health events were not significant for the $\mathrm{CEL}_{15}$ analysis. An incidence of MAST also significantly decreased $\mathrm{FE}_{15}$, and cows with an incidence of MAST were $5.2 \pm 2.2 \%$ less efficient at converting energy consumed into energy in milk than cows that did not have an incidence of MAST. A trend $(P=0.065)$ was observed for cows with KET to be more efficient at converting energy to energy in milk.

We did not find evidence of PREG differences by genetic group; however, fertility was numerically lowest in $\mathrm{HH}$, which agrees with results from other reports (Anderson et al., 2007; Heins et al., 2008). Our definition of fertility required a cow to be pregnant by 150 DIM and would not necessarily account for differences between genetic groups in days open. Heins et al. (2008) found that a greater portion of $\mathrm{JH}(75 \%)$ than $\mathrm{HH}(59 \%)$ were PREG. Our results are different, but all cows in this study were managed in a high-input confinement herd, whereas most of the cows in Heins et al. (2008) were in a low-input grazing herd. Environmental differences in the 2 studies could affect the results. de Vries et al. (1999) reported that large energy deficits in early lactation delayed first detected estrus. We found a trend for higher $\mathrm{CEB}_{15}$ to improve PREG status. de Vries et al. (1999) also found that first-lactation animals had less energy deficit than multiparous cows. Collard et al. (2000) found a relationship between the days in negative energy balance and reproductive problems. More days in negative energy balance increased the probability of reproductive problems. Our study of first-lactation performance may not have involved the extreme energy deficits in early lactation that would hinder fertility. Additionally, our measure of energy balance did not include the first 2 wk of lactation, which are typically when the cow experiences the largest deficit in energy balance.

Collard et al. (2000) found no statistically significant relationship between energy balance at d 100 in lactation and MAST. Banos et al. (2006) found significant genetic correlations for energy balance and SCC but found energy balance traits to be unrelated to clinical MAST. We found that cows with an incidence of MAST had lower intakes and decreased energy expenditures through lower production so the overall energy balance was not affected. However, $\mathrm{FE}_{15}$ was affected because

Table 4. Probability of a greater $F$ statistic and estimated effects of having each disease in the first $100 \mathrm{~d}$ of first lactation on $\mathrm{CEB}_{15}$, $\mathrm{CEI}_{15}$, $\mathrm{CEL}_{15}$, and $\mathrm{FE}_{15}{ }^{1}$

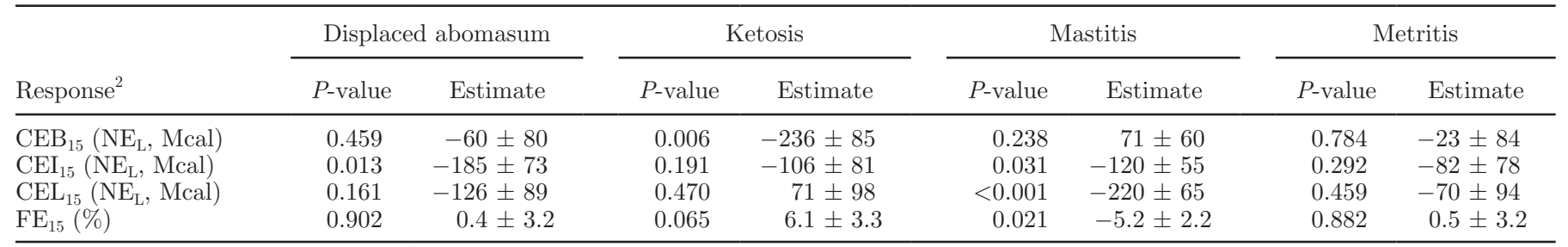

${ }^{1} \mathrm{CEB}_{15}=$ cumulative energy balance at wk 15 of lactation; $\mathrm{CEI}_{15}=$ cumulative energy intake at wk 15 of lactation; $\mathrm{CEL}_{15}=$ cumulative energy for lactation at wk 15 of lactation; $\mathrm{FE}_{15}=$ feed efficiency, defined as $\mathrm{CEL}_{15}$ divided by $\mathrm{CEI}_{15}$.

${ }^{2}$ Other effects in the model included genetic group, linear and quadratic for age at calving, and year-season freshening group. 
$\mathrm{CEL}_{15}$ decreased more than $\mathrm{CEI}_{15}$, resulting in a poorer feed efficiency ratio.

We did not observe an association between DA and $\mathrm{CEB}_{15}$. We measured $\mathrm{CEB}_{15}$ and recorded health events at any point within the first $100 \mathrm{~d}$, so cows could regain energy balance after the occurrence of the disease. Furthermore, feed intakes were not determined for cows that were clinically sick so estimates of feed intake came from cows that were considered healthy enough (by a veterinarian) to be using the Calan doors. Of 15 cows with an incidence of DA, 5 experienced an occurrence during an intake period and were removed from Calan doors for that period. Estimating $\mathrm{CEB}_{15}$ could have allowed cows to recover from diseases earlier in lactation. Milk production would be expected to decrease rapidly following lower feed intakes that accompany a disease event, which would have decreased energy expenditure and would, therefore, have small effects on energy balance.

A positive association was found between incidence of KET and $\mathrm{FE}_{15}$. This is likely an artifact of the manner in which $\mathrm{FE}_{15}$ is defined. Cows with KET were mobilizing body tissue to support milk production, as evidenced by the strong relationship between $\mathrm{CEB}_{15}$ and KET. Cows with KET may actually have lower efficiency because the feed required to deposit body tissue is greater than the amount of energy available to support production when that tissue is subsequently mobilized.

Genetic group and year-season freshening group significantly affected $\mathrm{CEI}_{15}$ and $\mathrm{CEL}_{15}$, but genetic group was not significant in $\mathrm{CEB}_{15}$. In a previous study (Olson et al., 2010), these genetic groups were statistically different for amount of energy consumed and amount of energy used for milk production, but not for energy balance in mid-lactation. In the current study, $\mathrm{CEI}_{15}$ was affected by genetic group, MAST, and DA, but compensatory reductions in milk yield left $\mathrm{CEB}_{15}$ unaffected by those factors.

In conclusion, no differences between the genetic groups for incidence of KET, DA, and PREG were observed. The HJ were more likely to have an occurrence of MAST than the HH. Cows with higher $\mathrm{CEB}_{15}$ (less severe negative energy balance) tended to have higher odds of becoming PREG. We observed a trend for crossbreds (HJ and $\mathrm{JH}$ ) to be less likely than the $\mathrm{HH}$ to have an occurrence of MET. An incidence of KET decreased $\mathrm{CEB}_{15}$, whereas the other health disorders did not affect energy balance. An incidence of MAST reduced intakes, milk production, and feed efficiency, but did not affect energy balance because the declines in feed intake and milk production were enough to compensate. We saw few differences in disease incidences by genetic group with our small sample size.

\section{ACKNOWLEDGMENTS}

The authors thank the farm staff at Virginia Tech dairy (Blacksburg). The authors are grateful for the financial support provided by Holstein Association USA (Brattleboro, VT), the American Jersey Cattle Club Research Foundation (Reynoldsburg, OH), the Animal Improvement Programs Laboratory (ARS, USDA, Beltsville, MD), and the Virginia State Dairymen's Association (Harrisonburg).

\section{REFERENCES}

Anderson, T., R. Shaver, P. Bosma, and V. De Boer. 2007. Case Study: Performance of lactating Jersey and Jersey-Holstein crossbred versus Holstein cows in a Wisconsin confinement dairy herd. Prof. Anim. Sci. 23:541-545.

Banos, G, M. P. Coffey, E. Wall, and S. Brotherstone. 2006. Genetic relationship between first-lactation body energy and later-life udder health in dairy cattle. J. Dairy Sci. 89:2222-2232.

Berry, D. P., F. Buckley, P. Dillon, R. D. Evans, M. Rath, and R. F. Veerkamp. 2003. Genetic relationships among body condition score, body weight, milk yield, and fertility in dairy cows. J. Dairy Sci. 86:2193-2204.

Collard, B. L., P. J. Boettcher, J. C. M. Dekkers, D. Petitclerc, and L. R. Schaeffer. 2000. Relationships between energy balance and health traits of dairy cattle in early lactation. J. Dairy Sci. 83:2683-2690.

de Vries, M. J., S. Van Der Beek, L. M. T. E. Kaal-Lansbergen, W. Ouweltjes, and J. B. M. Wilmink. 1999. Modeling of energy balance in early lactation and the effect of energy deficits in early lactation on first detected estrus postpartum in dairy cows. J. Dairy Sci. 82:1927-1934.

Dunklee, J. S., A. E. Freeman, and D. H. Kelley. 1994. Comparison of Holsteins selected for high and average milk production. 2. Health and reproductive response to selection for milk. J. Dairy Sci. 77:3683-3690.

Hansen, L. B. 2000. Consequences of selection for milk yield from a geneticist's viewpoint. J. Dairy Sci. 83:1145-1150.

Heins, B. J., L. B. Hansen, and A. J. Seykora. 2006. Fertility and survival of pure Holsteins versus crossbreds of Holstein with Normande, Montbeliarde, and Scandinavian Red. J. Dairy Sci. 89:4944-4951.

Heins, B. J., L. B. Hansen, A. J. Seykora, D. G. Johnson, J. G. Linn, L. E. Romano, and A. R. Hazel. 2008. Crossbreds of Jersey x Holstein compared with pure Holsteins for production, fertility, and body and udder measurements during first lactation. J. Dairy Sci. 91:1270-1278.

Kasimanickam, R., R. L. Nebel, I. D. Peeler, W. L. Silvia, K. T. Wolf, A. J. McAllsiter, and B. G. Cassell. 2006. Breed differences in competitive indices of Holstein and Jersey bulls and their association with sperm DNA fragmentation index and plasma membrane integrity. Theriogenology 66:1307-1315.

National Research Council. 2001. Nutrient Requirements of Dairy Cattle. 7th rev. ed. Natl. Acad. Sci., Washington, DC.

Olson, K. M., B. G. Cassell, and M. D. Hanigan. 2010. Energy balance in first-lactation Holstein, Jersey, and reciprocal F1 crossbred cows in a planned crossbreeding experiment. J. Dairy Sci. 93:4374-4385.

SAS Institute. 2004. SAS/STAT Software. Release 9.1.3. SAS Inst. Inc., Cary, NC.

Weigel, K. A., and K. A. Barlass. 2003. Results of a producer survey regarding crossbreeding on U.S. dairy farms. J. Dairy Sci. 86:4148-4154.

Zwald, N. R., K. A. Weigel, Y. M. Chang, R. D. Welper, and J. S. Clay. 2004. Genetic selection for health traits using producerrecorded data. I. Incidence rates, heritability estimates, and sire breeding values. J. Dairy Sci. 87:4287-4294. 